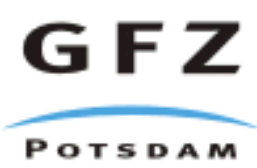

Originally published as:

Blöschl, G., Ardoin-Bardin, S., Bonell, M., Dorninger, M., Goodrich, D., Gutknecht, D., Matamoros, D., Merz, B., Shand, P., Szolgay, J. (2007): At what scales do climate variability and land cover change impact on flooding and low flows?. - Hydrological Processes, 21, 9, 1241-1247,

DOI: 10.1002/hyp.6669. 
as of Jan. 8, 2007

\title{
At what scales do climate variability and land cover change impact on flooding and low flows?
}

\author{
Günter Blöschl ${ }^{1}$, Sandra Ardoin-Bardin², Mike Bonell ${ }^{3}$, Manfred Dorninger ${ }^{4}$, David \\ Goodrich $^{5}$, Dieter Gutknecht ${ }^{1}$, David Matamoros ${ }^{6}$, Bruno Merz ${ }^{7}$, Paul Shand ${ }^{8}$, Jan Szolgay ${ }^{9}$
}

${ }^{1}$ Institute of Hydraulic and Water Resources Engineering, Vienna University of Technology, Karlsplatz 13, A-1040 Vienna, Austria, email: bloeschl@hydro.tuwien.ac.at

${ }^{2}$ UMR HydroSciences Montpellier, France

${ }^{3}$ UNESCO Division of Water Sciences, Paris, France

${ }^{4}$ University of Vienna, Austria

${ }^{5}$ USDA-ARS-SWRC, Tucson, AZ, USA

${ }^{6}$ FIMCM-ESPOL, Campus Gustavo Galindo, Guayaquil, Ecuador

${ }^{7}$ GeoForschungsZentrum Potsdam, Germany

${ }^{8}$ CSIRO Land and Water, Glen Osmond, Australia

${ }^{9}$ Slovak University of Technology, Bratislava, Slovakia

\section{INTRODUCTION}

Land cover, typically, is a local phenomenon, so the impact of any disturbance is likely to strongly decrease with catchment size. The position in the landscape will modulate the scale effects. In contrast, climate impacts may occur at larger scales so one would expect them to be apparent in both small and large catchments and be consistent in a region. River training impacts are likely to increase with catchment size as there is a general tendency for larger settlements and hence large scale flood protection works at larger streams. The schematic of Fig. 1 visualises hypothesised relative roles of climate and land use changes. The crossover point on the figure is likely to vary from catchment to catchment as hydrology is a context dependent discipline, i.e. it matters where / when / how processes occur. For example, land cover effects in the tropics are fundamentally different from those in humid climates as, typically, erosion plays a much more important role (Bonell and Bruijnzeel, 2005). In different hydrological settings the impacts will become important at different scales. For the particular case of the Sahel, Mahé et al. (2005a) suggest that environmental change effects in runoff stem, in equal parts, from climate oscillation and land cover changes. However, very little is known on the scales of impact of the various controls that can be generalised to different environments. 


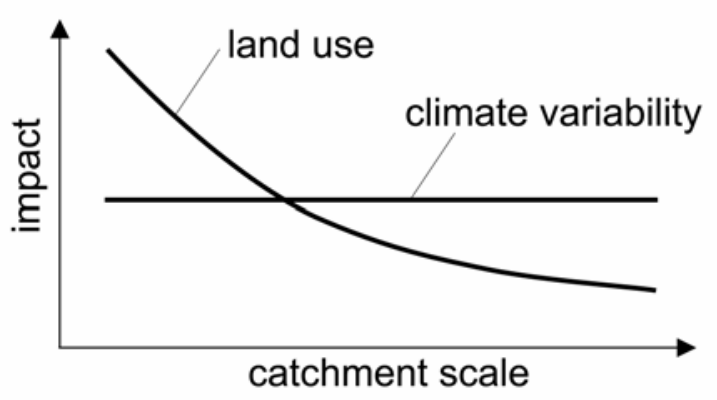

Figure 1. Hypothesised impact of land use and climate variability on hydrological response as a function of scale.

The UNESCO Division of Water Sciences has therefore initiated a working group on identifying the relative role of climatic variability and land cover change on floods and low flows as a function of spatial scale. The mandate of the working group is to summarise the state of the art of the subject, develop the key science questions, plan a five year research strategy for testing in HELP basins and other research experimental basins, and plan a series of workshops. This paper summarises the findings of a working group meeting held in Vienna during November 28-30, 2005 to provide a road map of how to address these issues and act as a catalyst for motivating communication and targeted research.

There are two main approaches to address the issue (Sivapalan et al. 2003). The first is the upward or mechanistic approach which, in the present context, consists of model cascades with each of the models representing sub-processes such as rainfall processes, flow in the subsurface, etc. This approach is amenable to analysing causal controls but the result is largely a reflection of the assumptions involved, including model structure. Interrelationships and scale effects may be difficult to capture, and it may be difficult to define the model structure and the parameters in a realistic way. The second approach is the downward approach which in the present context consists of trend analyses of long runoff data series and paired catchment studies. Its strength is to capture the summary effect of all controls but it is difficult to identify the causality, as the data may be ambiguous. FAO (2000, p. 2) noted: "As a general rule, impacts of land use activities on hydrological and sediment-related processes can only be verified at smaller scales (up to some tens of square kilometres) where they can be distinguished from natural processes and other sources of degradation. Assumptions that relationships observed at smaller scales hold at the largest scales, and that processes observed in one particular region can be applied to another, have often led to inappropriate and ineffective responses, because different processes are dominant at different scales. Certain impacts of land use on water quality, such as salinity, have an impact at larger scales as well. At the largest scales, impacts are difficult or impossible to verify because of a long time lag between cause and effect, and many overlapping factors." It is clear that both the upward and downward approaches need to be pursued to exploit their respective strengths. A caveat needs to be added to both types of analysis, however. There is a general notion that hydrological events have become more extreme in recent years as flagged out by recent exceptional events. However, a causal interpretation needs to be treated with caution as extreme floods tend to cluster into groups of several years. This has been the case for centuries. Also, there may exist biases both towards and against the apparent occurrence of more extreme events. One of the potential biases is a tendency for selecting catchments with recent extremes for hydrological analyses while not examining catchments where such extremes have not occurred recently. 
There is a rich literature on climate change and climate change impact on water resources. Relevant publications include Lall (2005), Pittock (2002), Trenberth (1999), Benestad (2003), Beniston et al. (1997), Hanson et al. (2004), Svensson et al. (2005), Hisdal et al. (2001), and Llasat et al. (2005). Similarly, there have been numerous publications on land cover change effects on floods, low flows and, more generally water yield, including Robinson et al. (2003), Brown et al. (2005), Andréassian (2004), Cosandey et al. (2005), Bonell and Bruijnzeel (2005), Bonell (1999), Mahé et al. (2005b), Archer (2003), Jones (2000), Bronstert et al. (2002) and Pfister et al. (2004). Rodriguez-Iturbe (2000), Peterson et al. (2000), Woods (2005) and Anderson et al. (2005) provide perspective on hydrological variability and other background information highly relevant to the issue of scales of climate variability and land cover change impact on flooding and low flows. On the basis of these publications and other experience, the working group has identified a number of key topics that should be addressed to further insights into the science questions.

\section{CHANGE AND METHODS OF CHANGE ANALYSIS}

From a methodological perspective, the concept of change is central to the issues of climate variability and land cover change impact on flooding and low flows. The concept therefore needs to be scrutinised both in terms of the processes involved and in terms of the methods that are useful in analysing change. In the context of floods and low flows, agents of change include fire, salinisation, agriculture (including animal activities), urbanisation, forest conversion, climate, use of water resources, subsidence of the ground surface, infestation, pollution, socio-economic-political processes, etc. Abrupt changes in watershed response can occur as a result of land use change (e.g., through fire, agricultural practice, etc.) and can be particularly severe at small scales (e.g. housing development), but there are instances of tremendous large scale changes. One example is the trend reversal in nitrate concentrations of the Danube as a result of political changes in Eastern Europe in the 1990s. System behaviour in the context of change can be characterised by properties such as stability, resilience, reversibility or irreversibility of change, as well as hysteresis. For example, deforestation/forest fires may cause no immediate effect, but time lagged changes may occur due to a memory effect of soil characteristics which can lead to hysteretic processes. A difficulty, however, with downward, trend detection methods is the multiplicity of types of changes - changes in the mean, variances, extremes / outliers, trend changes, step changes, etc. The type of change may be closely related to the degree of non-linearity of the system as well as any feedback effects present in the system. From both a theoretical and applied perspective it would hence be of interest to ascertain the variables that are indicators of how the catchment will respond to changes. The controls may not always be obvious. For example, forest fires may change soils from hydrophilic to hydrophobic (fire-induced hydrophobicity) which may also affect soil structure.

\section{TRANSITIONAL CLIMATE REGIMES}

Transitional regimes involve changes over a spectrum of time scales. There seems to exist consensus among atmospheric scientists for projected air temperatures to increase in the next decades but rainfall trends are less clear. For some areas, such as West Africa, the outputs from atmospheric models differ hugely. Because of the differences between model outputs, selection of the appropriate model for impact analyses in a given region is important. There is also an interesting issue of how the variability of mean atmospheric characteristics is related to extremes such as heavy rainfall and dry spells. There are lines of reasoning that suggest that extremes will increase in the coming decades but, given the many non-linearities of the system, changes in the mean behaviour do not necessarily entail changes in the extremes. This 
issue is related to the applicability of the delta change approach that is sometimes used to scale the variability of historic data to projected conditions. Of key importance in assessing climate variability are El Niño/ENSO cycles. In some parts of the world, agricultural management decisions are made on the basis of El Niño predictions. False alarms may be costly and often it may be unclear who is to cover these costs. For example, 1997 was expected to be an El Niño year similar to 1982 in Ecuador but it then turned out to be less severe than anticipated. From a local scale management perspective, it would be of interest to relate sea surface temperature cycles to precipitation records and to map that influence spatially as done for various areas by Cayan et al. (1999) and Enfield et al. (2001). Other longer term sea-surface temperature oscillations such as the Pacific Decadal Oscillation (PDO) or the Atlantic Multi-Decadal Oscillation (AMO) can reinforce or dampen ENSO effects depending on season and location (McCabe et al., 2004). A shift in the frequency and intensity of precipitation, i.e. precipitation regimes, can alter the regime of hydrological flow paths and fluxes. Chappell and Sherlock (2005), for example, observed that sediment deposits in the river bed were remobilised during El Niño events. More generally, erosion mechanisms would be expected to change in a transient climate (see e.g. Nearing, 2001). Hydrological sensitivity to climate has mostly been studied through model sensitivity. Downscaling methods can be used to relate the output of atmospheric global circulation models to local rainfall characteristics (Blöschl, 2005). Alternatively, local and regional climate characteristics can be related on the basis of long historic records and these can be used for impact studies. The analogue method (e.g. Zorita and von Storch, 1999) may offer some potential for analysing the change issue by identifying historic situations that were similar to the projected changed situations in the future.

\section{CATCHMENT PROCESSES AND FLOW PATHS}

Land cover and climate variability effects on floods and low flows are strongly controlled by the flow paths in catchment systems that differ in their time scales and the degree of connectivity. In fractured aquifers, time scales are variable and can vary over centuries (Cook, 2003) while soil systems respond much more quickly. There are numerous models describing catchment flow, but few of them provide reliable information on the actual flow paths. There exists a good theoretical understanding of potential mechanisms, but for practical applications, knowledge of the mechanisms in any one catchment is needed. Current forest hydrology seems to be biased towards interception and there seems to exist a lack of information on subsurface flow systems in forests. There are two key issues. The first is: How do land use change and climate variability modify flow pathways and storage? The second, related, issue is: What are the changes in soil structure due to vegetation changes? Some soils tend to preserve properties of the forest for some time after clearing in particular environments (e.g. some Australian soils) but in other soil environments (e.g. the Amazon) soils tend to change much more quickly. A classification of soils in terms of its memory, i.e., the resilience of hydraulic characteristics to change would be of interest. Subsurface flow may manipulate decayed roots and the space around roots. In turn, there is an important role of microbes, insects, earthworms, etc., in flow path development and change. Rooting characteristics are important for recharge. For example, eucalypts can mine groundwater, and in the arid climate of Arizona, trees can tap water from $18 \mathrm{~m}$ below the surface because they have adjusted to a drier climate in former times. Mesquite trees in Arizona, when abundant, have been observed to redistribute surface soil moisture downward, in essence banking this water for later use and moving it below the reach of more shallow rooted inter-canopy competitors (Hultine et al., 2004). Vegetation change is often a localised change and the change effects are lost at larger scales. The areal fraction of changed land cover is an obvious control in the case of urbanisation but not necessarily so with the type of vegetation changes 
as some species may compensate for changed water availability. Also, the connectivity of flow paths within the catchments and the stream network may be a major determinant on how changed forcings translate into hydrological response. Different mosaics of land cover types exist and will impact in a complex way on low flows and floods.

\section{FEEDBACKS}

Catchment systems include a multitude of processes that interact to various degrees. In assessing the effects of changes in the inputs to the system output and/or the system characteristics, the way the components interact are important. One way of conceptualising the interactions is by feedback loops, i.e. either positive feedbacks that exaggerate a disturbance or negative feedbacks that stabilise the system. Both types of feedback loops may be operative in catchments although most of them are not very well understood. For example, land cover change will not only directly impact on runoff through affecting runoff generation processes but also indirectly through feedbacks with local climate (Pielke, 2005). Land surface soil moisture is a key variable in feedback mechanisms associated with climate effects. There are a range of feedback mechanisms associated with soil erosion/depletion and soil formation related to both climate and runoff generation. Some of the feedback loops are disrupted by human intervention (e.g. vegetation dynamics, soil formation). Other potential feedbacks include changes in albedo - changes in species; surface roughness - vegetation, infiltration; soil evolution - vegetation (long term feedbacks); erosion - vegetation change; erosion of stream deposits and river morphology - runoff characteristics; surface infiltration properties - shallow subsurface flow paths; groundwater - surface water interactions. Some of these feedbacks will probably be very important for assessing the impact of change on low flows and floods at various scales. Quantitative, coupled models are one way of assessing feedback effects and may assist in relating processes from different disciplines. Simpler methods include causal loop methods that are a qualitative way of analysing complex systems to identify feedback mechanisms (e.g. Cavana and Mares, 2004). The interesting thing about feedback mechanisms is that they are likely to exist at a wide range of spatial scales and that their effect may differ vastly from what one would expect intuitively.

\section{HETEROGENEITY AND SCALING}

As data never exhaustively represent the hydrological environment, heterogeneity and scale effects enter the scene in impact analyses. A key issue is how to combine measurements and models across a range of scales (Blöschl, 2006). There are a number of complications with this process - the information at the larger scales tends not to be as detailed as that in the local studies; there is a lot of variability at all scales in the boundary conditions and media characteristics, part of which may involve preferential flow (e.g. fractured rocks); and the governing equations may not be known at all scales. Preferential flow and multiscale heterogeneity may induce scale effects. An example related to the dimensionality of the system is that borehole pumping tests in aquifers often show higher transmissivities than cores; however, smaller transmissivities are more consistent with regional-scale models. There is an analogy between spatial heterogeneity at all spatial scales and clustering of events in time which is tantamount to the presence of variability at all temporal scales. There have been a host of publications in the past decade that address scale issues in hydrology although many open questions remain. Indeed, the use of point data (e.g. on soils) at the catchment scale is questioned by many because of a lack of representativeness. There exist alternatives, such as use of hillslope response indices rather than local scale soil characteristics or, generally, the use of small scale information (e.g. chemical data) at the large scale in a qualitative way to assist in conceptualisations. Spatial patterns of hydrological response may 
assist in identifying internal catchment dynamics (Grayson and Blöschl, 2000) which is another alternative to the straightforward upscaling of point data to the catchment scale. In the context of the implications of the current science question, an important issue is how changes in the hydraulic characteristics of soil, due to vegetation changes, transfer to larger scales and what is the interplay of groundwater dynamics and stream flow dynamics in response to changed land cover and climate variations. This is related to the feedback issues mentioned above. Of general interest is how one can upscale local information on soils, vegetation, groundwater and surface water - groundwater interactions to the scale of HELP basins $\left(10000 \mathrm{~km}^{2}\right)$ ?

\section{GENERALISATION AND POTENTIAL OF TYPOLOGIES}

As mentioned above, hydrology is a data limited discipline so, in a sense, all catchments of the world are data sparse. However, in developing countries data density is particularly low. How to best overcome data scarcity to assess the impacts on the water resource due to land cover change and climatic variability is an issue in both developing and developed countries although the level of data scarcity is different. Alternatives to expensive instrumentation are therefore needed. Ideally, one would have available simple methods that allow identification of the dominant processes in any one catchment with limited measurements. There exist a number of low cost options for measuring hydrological response at various scales. One example at the small catchment scale are simple tubes used as overland flow indicators (Vertessy et al., 2000). At larger scales, low cost monitoring strategies may involve enlistment of volunteers, such as in a successful programme with primary school teachers in Ecuador. There are examples where the basin community has been mobilised by experts to conduct simultaneous spot measurements of flow and water quality. The GLOBE program is an example programme that provides web-based measurement protocols for science school teachers.

Optimising measurement strategies is another corner stone of addressing the data scarcity issue. Nested basins at different scales with extra equipment in some of the catchments are useful to examine scale issues. Hydrological observatories based on this philosophy have been established or will soon be established in a number of countries including the UK and the US (e.g. by the CUAHSI initiative). Monitoring issues are highly relevant to management, e.g. how to give guidance on the necessary regulations given a monitoring network or, conversely, what is the necessary network density to address a management problem such as the ecological consequences of catchment development in a stream.

Some data types are relatively easy to obtain, so another variant of optimising the measurement strategy is a prudent choice of the variables to be sampled. For example, data sets of land use change can be obtained from satellites, historic photos, and phenology data. More generally, important issues are whether one can identify variables that should be strategically collected that would more directly address impact on hydrological response, i.e., where does one best spend moneys to obtain maximum hydrological insight. Tradeoffs are likely to exist in many cases, e.g., raingauges vs. isotopes. Other variables than those usually measured can offer greater sensitivity to change and should therefore be given priority in monitoring design. In arid environments, for example, erosion is much more sensitive to land cover change than is runoff. Flow paths are much more difficult to assess in data sparse regions. In the developing world there is little knowledge on groundwater and the limited knowledge focuses on resources, i.e., on aquifer yield. What would help to exploit the information from geological maps more effectively are groupings of the geological settings by structure, storage, and or residence times. 
If data are scarce, surrogate measures or indices are often extremely useful. Indices are usually designed to represent the main drivers or effects in a particular context with a minimum of information required. Such indices can be based on similarity measures across a landscape focussing on what makes patches of the landscape similar to other patches in terms of hydrological response, what makes aquifers similar to others or, more generally, what makes two catchments similar. Examples of indices include terrain indices to tag processes as a function of landscape position and flash flood guidance indices to tag rainfall intensities needed to produce a flood of a given magnitude (Georgakakos, 2006). Indices can be developed through both the upward and downward approaches. In a downward approach one usually classifies the objects of interest into types or classes to obtain a typology. In the absence of detailed data one can then make educated guesses about the characteristics of a catchment or aquifer by knowing to which type they belong. A typology may help in generalising findings from experimental catchments and is one method of dealing with the context dependence of hydrology and with data scarcity. Indeed, in the past century there have been numerous process studies in small catchments and these need to be generalised to catchments where no detailed observations or no observations at all are available. The IAHS decade on the prediction in ungauged basins has a theme on basin inter-comparison and classification which could greatly contribute to the development of typologies (IAHS, 2005).

Typologies may be useful for a range of hydrological processes including climate/rainfall, catchments, geology, aquifers, soils and vegetation. Different atmospheric systems produce different rainfall characteristics and hence different responses of catchments. A catalogue of catchment types, in terms of flow paths, runoff mechanisms and hydrological regimes would be of great value (Woods, 2002). In a similar vein, a world-wide catalogue of aquifer facies geometry and properties, which could combine site genesis and description with methods used to assess the system, would be of great value for practical applications (de Marsily et al, 2005).

\section{SUMMARY}

To provide a road map of how to address the issues of climate variability and land cover change impact on flooding and low flows, the working group has singled out a number of specific research questions. These are given below for each of the themes discussed above.

Change and methods of change analysis

- What do various earth-sciences consider change?

- How do they deal with it?

- What are the results of agents of change on hydrological response, and time scales of change?

- What are suitable methods of change analysis/detection?

- When does the delta change approach (or incremental change approach) fail?

Transitional climate regimes

- How can one best use climate model results in view of the scale gap?

- How does uncertainty propagate from climate to hydrological models?

- How can analyses by the analogue method be combined with results from climate models?

- If circulation patterns change - does this decrease/increase floods?

- How can one relate changes of the mean atmospheric characteristics to changes of the extremes? 
Catchment processes and flow paths

- How do land use change and climate variability modify flow pathways and storage?

- What are the changes in soil structure due to vegetation changes (e.g. break down of fabric, mineralogy)?

- What are the changes in the time scales, e.g., over what time scales does soil structure change occur in response to land cover change?

- What is the resilience of soil hydraulic characteristics to change?

- What is the recharge for different settings and how does it change with climate/land use changes?

Feedbacks

- How do floods and low flows change with time and what are the feedback mechanisms controlling them?

- What feedbacks of land cover / climate impacts on water resources exist?

- What are the positive and negative feedback loops?

- How does the water balance affect runoff components (interactions between long and short time scales)?

- What are the changes in the coupling between groundwater and surface water linked with land cover change?

Heterogeneity and scaling

- What percentage of catchment area can be changed to another land cover type before a significant change in the flood regime occurs?

- How do changes in the hydraulic soil characteristics due to vegetation changes transfer to larger scales?

- How can one upscale local information on soils, vegetation, groundwater and groundwater - surface water interactions to the scale of HELP basins $\left(10000 \mathrm{~km}^{2}\right)$ ?

- What are integrative concepts of upscaling/downscaling in the context of impact analyses?

- What is the relative role of climatic variability and land cover change on floods and low flows as a function of scale in different environments?

Generalisation and potential of typologies

- How can climate/rainfall, catchments, aquifers, soils and vegetation be classified (with a view on floods and low flows)?

- What processes switch between regimes (in time, spatially)?

- How to best overcome data scarcity to assess the impacts on the water resource due to land cover change and what are low cost options for measuring hydrological response at various scales?

- What is the necessary network density to address a management problem such as the ecological consequences in a stream of catchment development?

- What variables should be strategically collected that would more directly address impact on hydrological response?

\section{ACKNOWLEDGEMENTS}


The first author would like to thank Mike Bonell for his enthusiasm, energy and advice in establishing this working group.

\section{REFERENCES}

Anderson, M.G. et al. (Eds.) (2005) Encyclopedia of Hydrological Sciences, J. Wiley \& Sons, Chichester, 3243 pp.

Andréassian, V. (2004) Waters and forests: from historical controversy to scientific debate. Journal of Hydrology 291, 1-27.

Archer, D. (2003) Scale effects on the hydrological impact of upland afforestation and drainage using indices of flow variability. Hydrology and Earth Systems Sciences 7, 325-338.

Benestad, R. E. (2003) What can present climate models tell us about climate change? Climatic Change 59, 311-331.

Beniston, M., H. F. Diaz, R. S. Bradley (1997) Climatic change at high elevation sites: an overview. Climatic Change 36, 233-251.

Blöschl, G. (2005) Statistical upscaling and downscaling in hydrology. Article 9 in: Encyclopedia of Hydrological Sciences, M. G. Anderson et al. (Eds.), J. Wiley \& Sons, Chichester, pp. 135-154.

Blöschl, G. (2006) Hydrologic synthesis: Across processes, places, and scales, Water Resources Research, 42, W03S02, doi:10.1029/2005WR004319.

Bonell, M. (1999) Tropical forest hydrology and the role of the UNESCO international hydrological programme. Hydrology and Earth System Sciences, 3, 451-461.

Bonell, M. and L. A. Bruijnzeel (eds) (2005) Forests, water and people in the humid tropics: past, present and future. Hydrological research for integrated land and water management. Cambridge University Press, 944pp.

Bronstert, A., Niehoff, D., Bürger, G. (2002) Effects of climate and land-use change on storm runoff generation: present knowledge and modelling capabilities. Hydrological Processes 16, 509-529.

Brown, A., Zhang, L. McMahon, T., Western, A., Vertessy, R. (2005) A review of paired catchment studies for determining changes in water yield resulting from alterations in vegetation. Journal of Hydrology 310, 28-61.

Cavana, R.Y. and Mares E.D (2004) Integrating critical thinking and systems thinking: from premises to causal loops. System Dynamics Review 20, 223-235.

Chappell, N.A. and Sherlock, M.D. (2005) Contrasting flow pathways within tropical forest slopes of Ultisol soil. Earth Surface Processes and Landforms, 30, 735-753.

Cook P.G. (2003) A Guide to Regional Groundwater Flow in Fractured Rock Aquifers. Seaview Press, Henley Beach (South Australia), 108pp.

Cosandey, C., Andreassian, V., Martin, C., Didon-Lescot, J., Lavabre, J., Folton, N., Mathys, N., Richard, D. (2005) The hydrological impact of the mediterranean forest: A review of French research. Journal of Hydrology 301, 235-249.

de Marsily, Gh., F. Delay, J. Goncalves, Ph. Renard, V. Teles, S. Violette (2005) Dealing with spatial heterogeneity. Hydrogeology Journal 13,161-183. 
Enfield, D.B., Mestas-Nuñez, A.M., and Trimble, P.J. (2001) The Atlantic multi-decadal oscillation and its relation to rainfall and river flows in the continental U.S. Geophysical Research Letters 28, 2077-2080.

FAO (2000) Land-water linkages in rural watersheds - Electronic workshop. 18 September 27 October 2000. Conclusions and recommendations. Food and Agriculture Organization of the United Nations. Rome, Italy.

Georgakakos, K. P. (2006) Analytical results for operational flash flood guidance. Journal of Hydrology, 317, 81-103.

Grayson, R. B. and G. Blöschl (Eds) (2000) Spatial Patterns in Catchment Hydrology: Observations and Modelling. Cambridge University Press, Cambridge, UK, 404 pp.

Hanson, R.T., M.W. Newhouse, M.D. Dettinger (2004) A methodology to assess relations between climatic variability and variations in hydrologic time series in the southwestern United States. Journal of Hydrology 287, 252-269

Hisdal, H., K. Stahl, L. Tallaksen and S. Demuth (2001) Have streamflow droughts in Europe become more severe or frequent? International Journal of Climatology 21, 317-333.

Hultine K.R., Scott R.L., Cable W.L., Goodrich, D.C., Williams D.G. (2004) Hydraulic redistribution by a dominant, warm-desert phreatophyte: seasonal patterns and response to precipitation pulses. Functional Ecology 18, 530-538.

IAHS (2005) IAHS Newsletter November 2005, IAHS Press, Centre for Ecology and Hydrology, Wallingford, Oxfordshire, UK.

Jones, J. (2000) Hydrologic processes and peak discharge response to forest removal, regrowth, and roads in 10 small experimental basins, Western Cascades, Oregon. Water Resources Research 36, 2621-2642.

Kepner, W.G. Semmens, D.J., Bassett, S.D., Mouat, D.A., Goodrich, D.C. (2004) Scenario analysis for the San Pedro River, analyzing hydrological consequences of a future environment. Journal of Environmental Monitoring and Assessment, 94, 115-127.

Lall, U. (2005) Hydrologic change: a formal line of scientific inquiry. http://www.cuahsi.org/cyberseminars/Lall_final.pdf

Llasat, M.C, Barriendos, M., Barrera, A., Rigo, T. (2005) Floods in Catalonia (NE Spain) since the 14th century. Climatological and meteorological aspects from historical documentary sources and old instrumental records. Journal of Hydrology 313, 32-47.

Mahé, G., J. C. Olivry and E. Servat (2005a) Sensibilité des cours d'eau ouest-africains aux changements climatiques et environnementaux: extrêmes et paradoxes. IAHS Publ. 296, 169177.

Mahé, G., Paturel, J., Servat, E., Conway, D., Dezetter, A. (2005b) The impact of land use change on soil water holding capacity and river flow modelling in the Nakambe River, Burkina-Faso. Journal of Hydrology 300, 33-43.

McCabe, G.J., Palecki, M.A., and Betancourt, J.L. (2004) Pacific and Atlantic Ocean influences on multidecadal drought frequency in the United States: Proceedings of the National Academy of Sciences 101, 4136-4141.

Nearing, M.A. (2001) Potential changes in rainfall erosivity in the United States with climate change during the 21st Century. Journal of Soil and Water Conservation 56, 229-232.

Peterson, G.D. (2000) Scaling ecological dynamics: self-organization, hierarchical structure, and ecological resilience. Climate Change 44, 291-309. 
Pfister, L., Kwadijk, J., Musy, A., Bronstert, A. and Hoffmann, L. (2004) Climate change, land use change and runoff prediction in the Rhine-Meuse basins. River Research and Applications 20, 229-241.

Pielke Sr., R.A. (2005) Land use and climate change. Science, 310, 1625-1626.

Pittock, A.B. (2002) What we know and don't know about climate change: Reflections on the IPCC TAR. An editorial essay. Climatic Change 53, 393-411.

Robinson, M., A.-L. Cognard-Plancq, C. Cosandey, J. David, P. Durand, H.-W. Führer, R. Hall, M.O. Hendriques, V. Marc, R. Mccarthy, M. McDonnell, C. Martin, T. Nisbet, P. O'Dea, M. Rodgers, A. Zollner (2003) Studies of the impact of forests on peak flows and baseflows: a European perspective. Forest Ecology and Management 186, 85-97.

Rodriguez-Iturbe, I. (2000) Ecohydrology: a hydrologic perspective of climate-soil-vegetation dynamics. Water Resources Research, 36, 3-9.

Sivapalan, M., G. Blöschl, L. Zhang and R. Vertessy (2003) Downward approach to hydrological prediction. Hydrological Processes 17, 2101-2111.

Sivapalan, M., Takeuchi, K., Franks, S. W., Gupta, V. K., Karambiri, H., Lakshmi, V., Liang, X., McDonnell, J. J., Mendiondo, E. M., O'Connell, P. E., Oki, T., Pomeroy, J. W., Schertzer, D., Uhlenbrook, S., and Zehe, E. (2003) IAHS Decade on Predictions in Ungauged Basins (PUB), 2003-2012: Shaping an exciting future for the hydrological sciences, Hydrological Sciences Journal, 48, 857-880.

Svensson, C. Kundzewicz, Z. and Maurer, T. (2005) Trend detection in river flow series: 2. Flood and low-flow index series. Hydrological Sciences Journal 50 (5), 811-824.

Trenberth, K. E. (1999) Conceptual framework for changes of extremes of the hydrological cycle with climate change. Climate Change 42, 327-339.

Vertessy, R.A., H. Elsenbeer, Y. Bessard, and A. Lack (2000) Storm runoff generation in a small tropical rainforest catchment with spatially variable soil hydraulic properties. In: R. Grayson and G. Blöschl (eds.). Spatial Patterns in Catchment Hydrology: Observations and Modelling. Cambridge University Press, pp. 247-271.

Woods, R. (2002) Seeing catchments with new eyes. Hydrological Processes 16, 1111-1113.

Woods, R. (2005) Hydrologic concepts of variability and scale. Article 3 in: Encyclopedia of Hydrological Sciences, M. G. Anderson et al. (Eds.), J. Wiley \& Sons, Chichester, pp. 23-40.

Zorita E. and H. von Storch (1999) The analog method as a simple statistical downscaling technique: comparison with more complicated methods. Journal of Climate, 12, 2474-2489. 